\title{
EQUILIBRIUM
}

Quarterly Journal of Economics and Economic Policy

VOLUME 7 ISSUE 1, 2012

ISSN 1689-765X

\author{
Andrzej Cieślik* \\ University of Warsaw, Poland
}

\section{Multinational EnTERPRises, Foreign KNOWLEDGe SpILlovers and Host Country Wages**}

JEL Classification Codes: $J 31, F 21, F 23$

Keywords: capital inflows, foreign knowledge diffusion, multinational enterprises, wages

\begin{abstract}
In this paper we study how the expansion of multinational enterprises in the host country affects its wages using a general equilibrium factor specific framework for a small open economy with a flexible labor market. We identify three potential effects of MNE activity associated with the transfer of foreign knowledge, diffusion of this knowledge among indigenous firms and the inflow of capital from abroad. We show that the impact of multinational enterprises on wages in the host country depends on differences in capital intensity between multinational and local sectors, the amount of capital transferred to the host country from abroad and the magnitude of knowledge spillovers stemming from multinational activity to indigenous firms.
\end{abstract}

(C) Copyright Nicolaus Copernicus University Press

Date of Submission: February 26, 2011; date of acceptance: December 19, 2011

* Contact: e-mail: cieslik@wne.uw.edu.pl, Uniwersytet Warszawski, Wydział Nauk Ekonomicznych, ul. Długa 44/50, 00-241 Warszawa, Poland

** The author would like to thank the participants of the 6th Contemporary Issues in Economy International Conference held in Toruń on 13-14 May 2011 and an anonymous referee for the helpful remarks, suggestions and comments on the earlier version of this paper. 


\section{INTRODUCTION}

The effects of the activity of multinational enterprises (MNEs) on wages in the host economy have long been a controversial topic. On the one hand, early studies viewing the expansion of MNEs in the host economy mainly as the transfer of physical capital find their activity beneficial for the host countries due to more efficient allocation of resources that results in higher wages. On the other hand, the more recent literature stresses potentially negative consequences of foreign direct investment (FDI) due to the introduction of modern capital-intensive and labor-saving production technologies which may result in job destruction and falling wages in the host economy.

The contemporary literature views the activity of MNEs in a broader context, not just the international movement of capital but rather "....a set of economic activities or operations carried out in a host country by firms controlled or partly controlled by firms in some other (home) country. These activities are, for example, production, employment, sales, the purchase and the use of intermediate goods and fixed capital, and the carrying out of research". (Lipsey 2004, p. 334). According to this literature no movement of physical capital is necessary for FDI to take place. In particular, MNEs may combine their specific foreign knowledge with the local factors of production instead of transferring capital from the home country.

Therefore, most recent studies perceive access to proprietary knowledge based assets possessed by MNEs as the main source of benefits associated with their activity in host country economies. Although MNEs are the global leaders in innovation and important means of disseminating their productive knowledge all over the world the crucial issue is whether this foreign knowledge spills over onto indigenous firms in host economies. The empirical evidence on the spillover benefits stemming from the activity of MNEs is still ambiguous and seems country-specific. In particular, there is no agreement whether activities of multinational firms result in higher wage levels in host economies.

The main aim of this paper is to contribute to the theoretical debate on the impact of multinational firms on host-country wages. In particular, we identify the conditions that need to be satisfied for the host country to experience an increase in wages due to the activity of MNEs. In contrast to the previous literature to study this impact, we use a general equilibrium model for a small open economy with a flexible labor market. The analysis of the case of a labor market that is free of any imperfections and clears instantaneously can serve as a useful benchmark for studying the MNE effects of labor market liberalization. Following the recent literature, in this paper we focus on the stock of foreign knowledge transferred from parent firms to 
their overseas subsidiaries, instead of capital inflows, as the main measure of the MNE activity in the host economy.

The structure of this paper is as follows: in the next section we have discussed the model setup. Then we have studied the impact of increased foreign involvement on the resource allocation and the wage level in the host country. In the subsequent section, we have concentrated on the role of foreign knowledge spillovers in wage determination in the host country. The last section summarizes and concludes.

\section{MODEL SETUP}

To study the impact of the foreign knowledge transfer on the host country labor market we employ a theoretical framework based on the factor specific model developed by Caves (1971). This framework was used in many previous studies, including Batra and Ramachandran (1980), Batra (1986), Beladi and Choi (1995), and more recently Cieślik (2008), to mention just a few examples. In this framework the inflow of foreign knowledge may but does not have to be accompanied by the transfer of physical capital.

Following the previous literature, we denote sectors in which multinational and locally-owned firms operate by $X$ and $Y$, respectively. Both sectors employ two non-specific and locally supplied factors of production: capital $K$ and labor $L$ that are fully mobile within and between sectors. Although inputs of both non-specific factors are necessary to produce goods in both sectors we allow for some substitution between capital and labor in response to their relative factor price changes. For example, an increase in the relative price of labor would increase the intensity of capital in both sectors. In addition to inputs of non-specific factors the multinational sector requires also an input of a specific factor - foreign knowledge, denoted by $S$, which is transferred from the parent country.

However, in contrast to the earlier theoretical studies that focused on the consequences of various sources of factor market imperfections in the host country, especially the rigidities in its labor market caused by labor unions or minimum and efficiency wages, in the current study we assume that wages are not sticky and factor markets clear instantaneously. This allows us to compare the results of the previous studies with the case of flexible labor market in the host country. Therefore, this paper belongs to the normative class of theoretical models in economics that allow us to understand better the potential consequences of MNE activity when factor markets function properly and hence the "would-be" effects of labor market liberalization. 
The aggregate production functions of the multinational and the local sectors are given by:

$$
\begin{aligned}
& Q_{X}=F\left(K_{X}, L_{X}, S\right) \\
& Q_{Y}=g(S) G\left(K_{Y}, L_{Y}\right)
\end{aligned}
$$

where: $Q_{X}$ and $Q_{Y}$ denote the outputs of foreign and domestic sectors, respectively; $K_{i}, L_{i}$ the amounts of capital and labor employed in the $i$-th sector, respectively $i=X, Y ; S$ is the input of foreign knowledge used in the multinational sector, and $g(S)$ is the measure of the spillover effect from the multinational firms onto the locally-owned firms.

Following Batra and Ramachandran (1980, p. 279) $S$ can be treated as "...a state variable whose value in any instant of time depends on the past efforts at developing the specific skills possessed by the multinational firm" and assume that $S$ is measured not in terms of physical units but of some intangible abstract units. According to Beladi and Choi (1995, p. 678), "...the role of the intersectoral spillover effect is described by $g$, where marginal exists when $d g / d S>0$. Hence, the output elasticity of the intersectoral spillover can be defined as $(\mathrm{dg} / \mathrm{dS})(\mathrm{S} / \mathrm{g})=\varepsilon$, where $\varepsilon>0$ reflects the intersectoral spillover effect". In other words, it is assumed that this spillover effect is positively related to the stock of foreign knowledge available in the host economy, i.e. $g^{\prime}(S)>0$. The spillover effect can be interpreted as the Hicks-neutral technological progress which increases productivity of both non-specific factors employed in the local sector. To examine the spillover effect on resource allocation we closely follow Beladi and Choi (1995) and consider a linear spillover benefit function of the form:

$$
g(S)=a+b S
$$

where $a=1$, and $b \geq 0$. When $b=0$, there is no spillover effect and the production function of the local sector reduces to $Y=G\left(K_{Y}, L_{Y}\right)$ as in Batra (1986). This corresponds to the case when foreign knowledge is fully excludable and it does not diffuse among the local firms.

We assume that production functions in both sectors have standard neoclassical properties. In other words, they are monotone increasing, strictly concave and exhibit the property of constant returns to scale 
(CRS). ${ }^{1}$ Their main properties of production functions for multinational and local sectors can be expressed as follows:

$$
F_{i}>0, F_{i i}<0, F_{i j}>0
$$

for: $i, j=K, L, S$, and $i \neq j$.

$$
G_{i}>0, G_{i i}<0, G_{i j}>0,
$$

for: $i, j=K, L$, and $i \neq j$.

Due to the assumed linear homogeneity of production functions, the marginal products are homogenous of degree zero. From the Euler theorem it can be easily inferred that $F_{L L} L_{X}+F_{L K} K_{X}+F_{L S} S=0, F_{K L} L_{X}+F_{K K} K_{X}+$ $F_{K S} S=0, G_{L L} L_{Y}+G_{L K} K_{Y}=0, G_{K L} L_{Y}+G_{K K} K_{Y}=0 .{ }^{2}$ Therefore, $F_{L L} F_{K K}-$ $F_{K L}^{2}>0$ and $G_{L L} G_{K K}-G_{K L}^{2}=0$.

We assume profit-maximizing behavior of all firms in both sectors. It is assumed that multinational firms maximize their profits given prices of their products and given the factor rewards. The representative multinational firm chooses factor inputs $K_{X}$ and $L_{X}$ with the aim of maximizing its profits. The profit maximization problem of a representative multinational firm from its operations in the host country can be written as follows:

$$
\max _{K_{X}, L_{X}} \Pi_{X}=p_{X} X-w_{X} L_{X}-r_{X} K_{X}-F
$$

where: $p_{X}$ denotes the price of goods produced in sector $X, w_{X}$ the wage rate offered by multinational firms, $r_{X}$ the capital rental rate in the multinational

\footnotetext{
${ }^{1}$ In mathematical terms this means that the production functions are homogenous of degree one.

${ }^{2}$ The Euler theorem can be proved as follows. The definition of constant returns to scale implies that if we increase inputs z-times the final output also increases z-times, i.e. $F\left(z K_{X}, z L_{X}, z S\right)=z F\left(K_{X}, L_{X}, S\right)$. Differentiating both sides with respect to $\mathrm{z}$ and assuming that $\mathrm{z}=1$ we obtain $F_{L} L_{X}+F_{K} K_{X}+F_{S} S=0$.
} 


\section{Andrzej Cieślik}

sector and $F$ the fixed cost of transferring the specific factor $S$ from the parent to the host country.

The first order conditions for the profit maximization problem of the representative multinational firm are given by:

$$
\begin{aligned}
& p_{X} F_{K}\left(K_{X}, L_{X}, S\right)=r_{X} \\
& p_{X} F_{L}\left(K_{X}, L_{X}, S\right)=w_{X}
\end{aligned}
$$

Equations (7) and (8) are the standard equality conditions between the values of marginal products of factors of production and their rental rates. Equation (7) allows to determine the optimal employment of capital $K_{X}{ }^{*}$ given its rental rate $r_{X}$, while equation (8) allows to determine the optimal employment of labor $L_{X} *$ given the wage rate $w_{X}$.

Since the production function $F(\cdot)$ is linearly homogenous the equilibrium profit level of a representative multinational firm $\hat{\Pi}$ repatriated to the parent country is given by:

$$
\hat{\Pi}=p_{X} F_{S} S-F
$$

where: $F_{S}$ is the marginal product of knowledge. According to Batra (1986), $\hat{\Pi}$ constitutes simply an addition to the global profits of the multinational firm since utilization of knowledge in the host country does not diminish its use in the parent country.

Similarly, the profit maximization problem of local firms in the host country can be written as follows:

$$
\max _{K_{Y}, L_{Y}} \Pi_{Y}=p_{Y} Y-w_{Y} L_{Y}-r_{Y} K_{Y}
$$

where: $p_{Y}$ denotes the price of goods produced in sector $Y, w_{Y}$ the wage rate in the local sector, and $r_{Y}$ the capital rental rate in the local sector. 
We assume that the behavior of local firms is also neoclassical, i.e. they maximize their profits taking the prices of their products as well as factor prices as given. We obtain a standard set of the first order conditions describing the equality between the values of marginal products of capital and labor, and capital rental and wage rates, respectively:

$$
\begin{aligned}
& p_{Y} g(S) G_{K}\left(K_{Y}, L_{Y}\right)=r_{Y} \\
& p_{Y} g(S) G_{L}\left(K_{Y}, L_{Y}\right)=w_{Y} .
\end{aligned}
$$

The focus on aggregate labor market effects in this study justifies the use of price-taking behavior assumption for all firms. Without a loss of generality it can be further assumed that the relative price of goods produced in both sectors is constant and it can be normalized to unity so that $p_{X}=p_{Y}=1$. This assumption implies that the nominal factor rewards in the sets of first order conditions for multinational and local firms, (7)-(8) and (11)-(12) respectively, become real factor rewards expressed in terms of marginal products of capital and labor, rather than the nominal factor rewards.

If there are no imperfections in the capital market in the host country, capital rental rates must be the same in both sectors ${ }^{3}$ :

$$
r_{X}=r_{Y}=r .
$$

Similarly, if there are no imperfections in the labor market wage rates must the same in both sectors:

$$
w_{X}=w_{Y}=w .
$$

Moreover, it is assumed that in any instant of time the supplies of all factors of production in the host country are fixed and independent of their

\footnotetext{
${ }^{3}$ While Batra (1986) in his original study assumes that owners of capital may be more willing to lend to multinational firms than to local firms the subsequent studies such as Beladi and Choi (1995) or Cieślik (2008) drop this assumption. It can be easily shown that our results do not crucially depend on the existence of the interest rate differential.
} 


\section{Andrzej Cieślik}

rewards. The capital stock in the host country may be, however, positively related to the stock of foreign knowledge transferred from the parent country if the knowledge transfer is accompanied by the inflow of physical capital from abroad. The inflow of foreign knowledge may, but does not have to, be accompanied by the transfer of physical capital from abroad.

We assume full employment of all factors of production available in the host country:

$$
\begin{aligned}
& K_{X}+K_{Y}=\bar{K}(S) \\
& L_{X}+L_{Y}=\bar{L} \\
& S=\bar{S}
\end{aligned}
$$

where: $\bar{K}, \bar{L}$ and $\bar{S}$ are the stocks of capital, labor and foreign knowledge available in the host country, respectively.

In subsequent sections of the paper we undertake the comparative static analyses of the impacts of a foreign knowledge transfer and the extent of its diffusion among local firms on the changes in factor allocation between sectors, wages in the local sector and wages in the host country. Depending on the circumstances, this transfer may or may not be accompanied by foreign knowledge spillovers and inflows of physical capital from abroad.

\section{KNOWLEDGE TRANSFER, TECHNOLOGICAL CHANGE AND CAPITAL INFLOW}

In this section we study the impact of foreign knowledge transfer and foreign capital inflow on the host country labor market assuming that the local labor supply is fixed and the wage rate is perfectly flexible. The demand for labor in the multinational sector $L_{X}$ is determined by the first order condition (8), while the demand for labor in the local sector $L_{Y}$ is determined by the first order condition (12), discussed in Section 2. Assuming fixed labor supply $\bar{L}$ and full employment of labor in the host country, the competitive equilibrium wage $\mathrm{w}$ is then determined by the equating the total demand for 
labor, i.e. the sum of demand for labor by multinational and local firms, and the labor supply $\left(L_{X}+L_{Y}=\bar{L}\right)$.

The initial equilibrium allocation of non-specific factors of production between the multinational and the local sectors can be obtained by combining conditions (7) - (8), (11) - (12), (13) - (14) and (15) - (17). Solving the following system of two equations allows us to find the equilibrium allocation of factors of production among the multinational and local sectors as functions of the fixed model parameters:

$$
\begin{aligned}
& F_{K}\left(K_{X}, L_{X}, \bar{S}\right)=g(\bar{S}) G_{K}\left(\bar{K}(\bar{S})-K_{X}, \bar{L}-L_{X}\right) \\
& F_{L}\left(K_{X}, L_{X}, \bar{S}\right)=g(\bar{S}) G_{L}\left(\bar{K}(\bar{S})-K_{X}, \bar{L}-L_{X}\right) .
\end{aligned}
$$

To examine changes in the allocation of non-specific factors between sectors and the competitive wage in the local sector, in response to the increased stock of the specific factor, represented by a positive change in the parameter $\bar{S}$, we totally differentiate the modified factor market equilibrium conditions (18)-(19) and obtain the following matrix system:

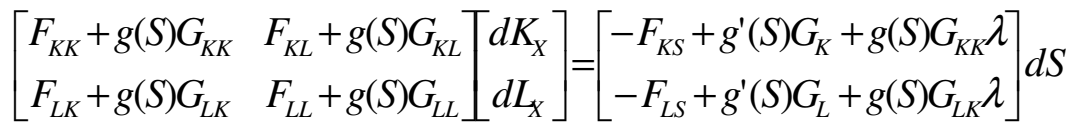

where: $\lambda=d K(S) / d S$ denotes the change in the physical capital stock available in the host country as a result of the capital inflow from abroad accompanying the foreign knowledge transfer.

The solutions of the system (20), obtained applying the Cramer's rule, show how the allocations of non-specific factors of production between the multinational and domestic sectors change as a result of the increased knowledge transfer from abroad, the accompanying foreign capital inflow and the diffusion of foreign knowledge among domestic firms. Following the previous theoretical studies, we investigate the effects of expansion of the multinational sector, assuming that it is more capital-intensive than the local one, i.e. $k_{X}>k_{Y}$. The changes in capital and labor employment in the multinational sector are given, respectively, by: 


$$
\begin{aligned}
& \frac{d K_{X}}{d S}=\frac{\left[F_{K L}+g(S) G_{K L}\right] F_{L S}-\left[F_{L L}+g(S) G_{L L}\right] F_{K S}}{\Delta}+\frac{g(S)\left[F_{L L} G_{K K}-F_{K L} G_{K L}\right] \lambda}{\Delta} \\
& +\frac{g^{\prime}(S)\left\{\left[F_{L L}+g(S) G_{L L}\right] G_{K}-\left[F_{K L}+g(S) G_{K L}\right] G_{L}\right\}}{\Delta}>0
\end{aligned}
$$

$$
\begin{aligned}
& \frac{d L_{X}}{d S}=\frac{\left[F_{K L}+g(S) G_{K L}\right] F_{K S}-\left[F_{K K}+g(S) G_{K K}\right] F_{L S}}{\Delta}+\frac{g(S)\left[F_{K K} G_{K L}-F_{K L} G_{K K}\right] \lambda}{\Delta} \\
& +\frac{g^{\prime}(S)\left\{\left[F_{K K}+g(S) G_{K K}\right] G_{L}-\left[F_{K L}+g(S) G_{K L}\right] G_{K}\right\}}{\Delta}=-\frac{d L_{Y}}{d S}>0
\end{aligned}
$$

where: $\Delta=\left(F_{K K} F_{L L}-F_{K L}^{2}\right)+g(S)\left[F_{K K} G_{L L}+F_{L L} G_{K K}-2 F_{K L} G_{K L}\right]>0$ is the main determinant of the matrix of derivatives of the marginal products of capital and labor.

The numerators on the right-hand side of the set of solutions (21)-(22) consist of three terms associated with the technology change due to the foreign knowledge transfer, the capital inflow from abroad and the foreign knowledge diffusion among local firms, respectively. The first two terms are positive, while the third term is negative. On the one hand, the impact of technology change in the host country economy due to the foreign knowledge transfer on employment changes of both non-specific factors of production is always positive. In addition to this, when the multinational sector is more capital intensive than the local one, the employment of these factors in this sector increases even more due to the capital inflow from abroad. On the other hand, the diffusion of foreign knowledge among local firms limits the extent of the expansion of the multinational sector. However, the magnitude of the first two effects is stronger than that of the third and the employment of both non-specific factors in the multinational sector increases, while in the local sector it falls.

As the labor supply in the host country is inelastic, the full employment condition (16) implies that the fall in the local sector employment corresponds to the increase in the multinational sector employment. At the same time, the full employment condition (15) implies that the change in the capital employment in the local sector can be calculated as the difference between the capital inflow from abroad and the increase in the capital employment in the multinational sector: 


$$
\begin{aligned}
& \frac{d K_{Y}}{d S}=\frac{d K(S)}{d S}-\frac{d K_{X}}{d S}=\frac{\left[F_{L L}+g(S) G_{L L}\right] F_{K S}-\left[F_{K L}+g(S) G_{K L}\right] F_{L S}}{\Delta}+ \\
& \frac{g(S)\left[H_{X}-g(S)\left(F_{K L} G_{K L}-F_{K K} G_{L L}\right)\right] \lambda}{\Delta}+ \\
& +\frac{g^{\prime}(S)\left\{\left[F_{K L}+g(S) G_{K L}\right] G_{L}-\left[F_{L L}+g(S) G_{L L}\right] G_{K}\right\}}{\Delta} \leq 0
\end{aligned}
$$

where: $H_{X}=F_{K K} F_{L L}-F_{K L}^{2}>0$.

The capital employment falls in the local sector as a result of the expansion of the multinational sector unless the capital inflow from abroad is sufficient to make multinational firms not to compete for capital in the local capital market. In such a case, there would be no relocation of capital from the local to the multinational sector. However, if the multinational firms do not transfer all the necessary capital for their operations in the host country from abroad, the larger is the inflow of capital from abroad and the bigger is the extent of foreign knowledge diffusion among the local firms, as well as the smaller is the fall in capital employment in the local sector.

The impact of the expansion of the multinational sector on the wage level in the host country can be determined by totally differentiating equation (8), substituting the solutions (21)-(22) of the system (20) and using the properties of the production functions discussed in the previous section:

$$
\begin{aligned}
& \frac{d w}{d S}=\frac{g(S) G_{K L}\left(k_{Y}-k_{X}\right)\left[F_{K L}\left(F_{K S}+F_{L S} / k_{X}\right)+F_{K S} F_{L S} S / K_{X}\right]}{\Delta}+\frac{g(S) H_{X} G_{K L} \lambda}{\Delta} \\
& +\frac{g^{\prime}(S)\left\{g(S) G_{K L}\left[F_{K L}\left(k_{X}-k_{Y}\right)+F_{L S} S / L_{X}\right]\left(G_{K}+G_{L} / k_{Y}\right)+H_{X} G_{L}\right\}}{\Delta}
\end{aligned}
$$

where: $k_{X}=K_{X} / L_{X}$ and $k_{Y}=K_{Y} / L_{Y}$.

If the multinational sector is more capital-intensive than the local one, $k_{X}$ $>k_{Y}$, the first term of expression (24) is negative, the second term is positive and the third term is also positive. This means that on the one hand the expansion of the multinational sector leads to a reduction in the demand for labor in the host country and a downward pressure on the wage level, while on the other hand the capital inflow from abroad and the diffusion of foreign knowledge lead to the increase in labor productivity and prevent wages from falling. Therefore, the impact of the expansion of the multinational sector on the wage level in the host country is ambiguous as it depends on interactions between the differences in capital intensity across sectors and 
the magnitude of the capital inflow and the extent of foreign knowledge spillovers. This impact can be different in the various stages of the FDI cycle proposed by Stern (1997): the initialization stage, the internationalization stage, and the mature investment stage.

In the initialization stage, the wage level in the host country may fall because neither significant foreign capital inflows from abroad nor foreign knowledge diffusion can be expected. This may be due to the fact that economic, legal and political environment may not be conductive to large FDI inflows. Foreign investors may face the risk of expropriation or insufficient intellectual property rights protection and may prefer to combine their specific knowledge with the local factors of production. Moreover, they may prefer to invest in traditional manufacturing activities, such as natural resource extraction, and transfer older technologies for which the scope of positive externalities associated with knowledge diffusion may be very limited.

In the internationalization stage foreign investors do not have to fear the risk of expropriation anymore and they may not even use the local capital market at all. Instead, they may bring all the necessary capital for their operations from the parent country where they may have an easier access to capital. When the capital stock in the local sector remains unchanged, but a part of the labor force in the host country moves to the multinational sector, the local sector becomes more capital intensive, the marginal product of labor increases and the wage level goes up.

Finally, in the mature investment stage, when multinational enterprises locate advanced high-technology activities for which the scope of positive externalities is large, the wage level in the host country may increase due to foreign knowledge spillovers onto local firms. The impact of the increased extent of foreign knowledge spillovers on resource allocation and the wage level in the host country is studied in detail in the next section.

\section{SPILLOVER EFFECT}

To take a closer look at the impact of the magnitude of the spillover effect $b$ on resource allocation we differentiate totally the equilibrium conditions (18)-(19) and use the properties of the spillover effect function (3). Noting that $d g / d b=S$ we obtain the following matrix system:

$$
\left[\begin{array}{cc}
F_{K K}+g(S) G_{K K} & F_{K L}+g(S) G_{K L} \\
F_{L K}+g(S) G_{L K} & F_{L L}+g(S) G_{L L}
\end{array}\right]\left[\begin{array}{c}
d K_{X} \\
d L_{X}
\end{array}\right]=\left[\begin{array}{c}
S G_{K} \\
S G_{L}
\end{array}\right] d b
$$


It can be easily noticed that the main determinant of the system (25) is positive and exactly the same as the determinant of the system (20). Applying the Cramer's rule, the solution of the system (25) yields:

$$
\begin{aligned}
& \frac{d K_{X}}{d b}=\frac{\left\{\left[F_{L L}+g(S) G_{l L}\right] G_{K}-\left[F_{K L}+g(S) G_{K L}\right] G_{L}\right\} S}{\Delta}<0 \\
& \frac{d L_{X}}{d b}=\frac{\left\{\left[F_{K K}+g(S) G_{K K}\right] G_{L}-\left[F_{K L}+g(S) G_{K L}\right] G_{K}\right\} S}{\Delta}<0 .
\end{aligned}
$$

Thus, the increase in the magnitude of the spillover effect limits the expansion of the multinational sector in the economy of the host country and encourages the local sector to employ more domestic resources.

Finally, the impact of the increased extent of foreign knowledge spillovers on the wage level in the host country can be determined by differentiating totally equation (8) and substituting the solutions (26) - (27) of the system (25). Using the properties of the production functions, we obtain:

$$
\begin{aligned}
& \frac{d w}{d b}=\frac{g(S) S G_{K L}\left\{\left[F_{K L}\left(k_{X}-k_{Y}\right)+F_{L S}\left(S / L_{X}\right)\right] G_{K}+\left[F_{K L}\left(k_{X} / k_{Y}-1\right)+F_{L S}\left(S / L_{X}\right)\left(1 / k_{Y}\right)\right] G_{L}\right\}}{\Delta} \\
& +\frac{S H_{X} G_{L}}{\Delta}>0 .
\end{aligned}
$$

If the multinational sector is more capital-intensive than the local one, $k_{X}>k_{Y}$, the above expression (28) is unambiguously positive. This means that the increase in the magnitude of the spillover effect results in the higher wage level.

\section{CONCLUSIONS}

In this paper we have studied the impact of the expansion of the multinational enterprises on the labor market in the host country using a simple two-sector three-factor general equilibrium model for a small open economy with a flexible labor market. We have identified three potential effects 
of multinational activity associated with the transfer of foreign knowledge and the associated technological change, the diffusion of this knowledge among local firms and the inflow of capital from abroad. In contrast to the previous studies we assumed a labor market that was free of imperfections and concentrated our attention on the impact of multinational firms on the wage level in the host country. This normative approach allowed us to understand better the "would-be" consequences of MNE activity in the case of labor market liberalization. In particular, it was shown that when the labor market clears instantaneously, there was adjustment in the wage level only, but not in the level of employment. The magnitude of the impact of MNE activity on the wage level in the host country depended on differences in capital intensity between the multinational and local sectors, the amount of capital transferred to the host country from abroad and the magnitude of knowledge spillovers stemming from multinational activity onto local firms. In particular, the bigger the extent of foreign knowledge spillovers the smaller the expansion of the foreign sector and the higher the wage level in the host country economy. The research hypotheses postulated by our theoretical framework should become a subject of empirical tests in the future work.

\section{LITERATURE}

Batra R.N. (1986), A General Equilibrium Model of Multinational Corporations in Developing Economies, "Oxford Economic Papers", Vol. 38, No. 2.

Batra R.N., Ramachandran R. (1980), Multinational firms and the theory of international trade and investment, "American Economic Review", Vol. 70, No. 3.

Beladi H., Choi E.K. (1995), On the Emergence of Multinational Corporations in Developing Economies: A Note, "Regional Science and Urban Economics", Vol. 25, No. 5.

Caves R.E. (1971), International Corporations: The Industrial Economics of Foreign Investment, "Economica", Vol. 38, No. 149.

Cieślik A. (2008), Multinational Firms, International Knowledge Flows, and Dual Labor Markets in Developing Economies, "Review of Development Economics", Vol. 12, No. 1.

Lipsey R.E. (2004), Home- and Host-Country Effects of Foreign Direct Investment, [in:] R.E. Baldwin, A.L. Winters (eds.), Challenges to Globalization: Analyzing the Economics, The University of Chicago Press, Chicago.

Stern R.E. (1997), Foreign Direct Investment, Exports and the East-West Integration: Theory and Practice, [in:] R.N. Cooper, J. Gács (eds.), Trade Growth in Transition Economies: Export Impediments for Central and Eastern Europe, Edward Elgar, Cheltenham. 